\title{
Tracheal rupture following blunt chest trauma presenting as endotracheal tube obstruction
}

Cynthia L. Henderson MD FRCPC, Sean R. Rose MD FRCPC

In this report, we describe a patient in whom a tracheal tear followed blunt thoracic trauma. The diagnosis was made late resulting in problems with ventilation, endotracheal tube obstruction and cardiac arrest. Difficulties with early recognition of tracheobronchial injuries may be caused by non-specific findings as well as the lack of exposure of physicians to patients with these injuries. The signs and symptoms of tracheobronchial injuries are described, as well as their differential diagnoses. A review of airway management has been made as it requires combined anaesthetic and surgical expenise. Injuries of the trachea may have severe, life-threatening consequences and early diagnosis and management reduce morbidity and mortality.

Cette observation décrit l'évolurion d'un patient victime d'une déchirure trachéale à la suite d'un traumatisme thoracique fermé. Des problèmes ventilatoires, une obstruction de la canule endotrachéale et un arrêt cardiaque ont orienté vers ce diagnostic. La difficulté de reconnaître précocement une blessure trachéobronchique peut provenir aussi bien de la non spécificité des symptômes que de l'expérience du médecin qui traite ce type de blessure. Les signes et symptômes des blessures trachéobronchiques sont détaillés ainsi que le diagnostic différentiel. On attire l'attention sur la gestion des voies aériennes qui nécessite autant de compétence de la part de l'anesthésiste que du chirurgien. Les blessures à la trachée peuvent avoir des répercussions graves et le diagnostic et une gestion précoces en réduisent la morbidité et la mortalité.

\section{Key words}

AIRWAY: obstruction;

COMPLICATIONS: trauma;

LUNG: trachea, rupture.

From the Department of Anaesthesia, St. Paul's Hospital, 1081 Burrand Street, Vancouver, B.C. V6Z 1Y6 and the Department of Anaesthesia, Peace Arch Hospital, 15521 Russell Avenue, Whiterock, B.C. V4B 2R6.

Address correspondence to: Dr. Cynthia L. Henderson. Accepted for publication 19th May, 1995.
In all trauma cases, basic rescucitation begins with the establishment and maintenance of an adequate airway. If blunt thoracic trauma has occurred, one should always consider the possibility of concomitant tracheal injury. Unfortunately, more common injuries associated with trauma may produce similar findings and divert one's attention from the less frequent tracheobronchial trauma.

The following case demonstrates the importance of a high index of suspicion in making the diagnosis of tracheobronchial injury following blunt trauma to the chest.

\section{Case report}

A 64-yr-old man was evaluated following blunt chest trauma. A hydraulic garbage container fell, crushing his chest between the container and the ground. The patient and a co-worker lifted the container and the patient walked home. He presented to the Emergency Department of a community hospital two hours later with respiratory distress and hypotension. His trachea was intubated, intermittent positive-pressure ventilation commenced and he received adrenaline. Bilateral chest tubes were inserted because of the potential for tension pneumothoraces.

After stabilization he was transferred and evaluated by the Trauma Service. At that time, his blood pressure was low at $80 / 50 \mathrm{mmHg}$ and femoral arterial and venous lines were inserted for diagnosis and management.

The portable chest $x$-ray taken on admission revealed a pneumomediastinum, bilateral multiple rib fractures, bilateral chest tubes with no pneumothoraces, and extensive subcutaneous emphysema along the chest wall. The endotracheal tube was in a good position. A Computer Assisted Tomography (CT) Scan in Emergency showed a large pneumomediastinum, subcutaneous air, and a right pneumothorax. The patient was transferred to the Surgical Intensive Care Unit haemodynamically stable. On arrival, his blood pressure decreased to $80 /$ $50 \mathrm{mmHg}$ and a needle thoracostomy was performed followed by the insertion of two additional chest tubes. The patient's condition worsened and his oxygen satu- 
ration decreased. His lungs became more difficult to ventilate and increased resistance was noted when manually ventilating them with an Ambu bag, ruling out problems with the mechanical ventilator. A suction catheter was passed easily down the endotracheal tube beyond the tip and a large blood clot was removed. His ventilation improved but his blood pressure decreased to $70 \mathrm{mmHg}$ systolic and he developed electromechanical dissociation (EMD). CPR was initiated. Before the arrest, the patient had received $7 \mathrm{~L}$ crystalloid in the SICU and, thus, hypovolaemia was not considered to have caused the EMD. The differential diagnosis included tension pneumothorax and pneumomediastinum, cardiac tamponade, myocardial contusion and hypoxia. Epinephrine $1 \mathrm{mg} i v$ was given which increased the systolic blood pressure to 120 $\mathrm{mmHg}$. Bronchoscopy was performed immediately and a tracheal tear was found. The endotracheal tube was inserted past the tear under direct vision and the patient's condition quickly stabilized.

The patient was transferred to the operating room where he was found to have an almost complete disruption of the distal trachea. The continuity of the trachea had been maintained by a $5 \mathrm{~mm}$ portion of membranous trachea in the midline of the posterior tracheal wall. Anaesthesia was maintained with isoflurane, opioids, and muscle relaxants using positive-pressure ventilation. At the level of the innominate artery, 3-0 Vicryl was used in an interrupted fashion to suture the trachea. The endotracheal tube was left in position with the cuff inflated below the tear during the tracheal repair. Following the repair, the endotracheal tube was pulled back until the tip lay proximal to the suture line to minimize pressure on the repair site.

Postoperatively the patient continued to have a stormy course. The following day he had a traumatic false aneurysm of the aortic arch repaired which was found on review of the initial CT scan. The patient required positive-pressure ventilation for two weeks postoperatively due to rib fractures, pulmonary contusions and Adult Respiratory Distress Syndrome before being successfully weaned from the ventilator. At the time of discharge from the Surgical Intensive Care Unit, the chest $x$-ray showed an elevated left hemidiaphragm with bilateral pleural effusions. He was discharged home 19 days post-injury with no apparent sequelae.

When the initial CT scan was reviewed, higher cuts showed the endotracheal tube inside the tracheal lumen but, just above the carina, the distal tip was clearly outside the lumen (Figure).

\section{Discussion}

Traumatic injuries of the tracheobronchial tree range from asymptomatic to fatal. ${ }^{1}$ Blunt trauma to the neck

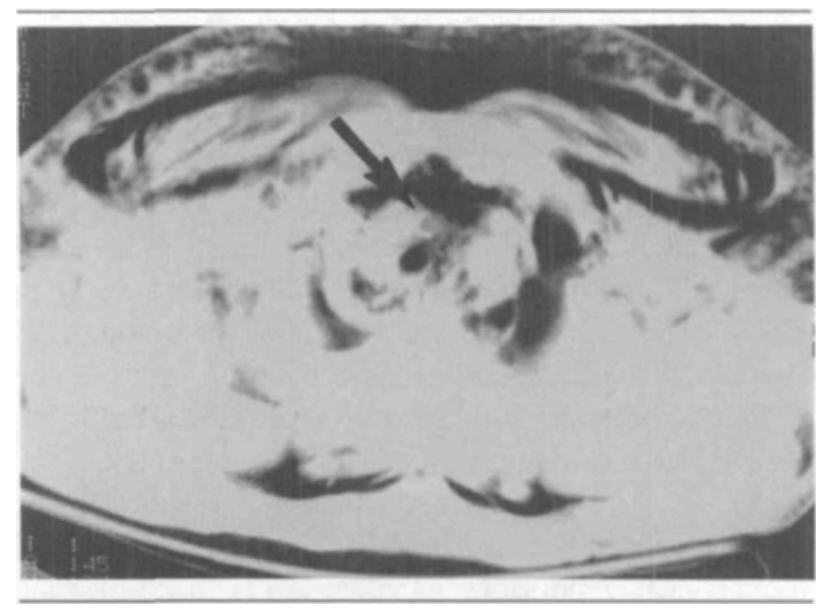

FIGURE CT scan showing endotracheal tube (arrow) outside the tracheal lumen.

or chest during motor vehicle accidents accounts for $80 \%$ of injuries to the larynx or the tracheobronchial tree ${ }^{2}$ and early diagnosis and management reduce the morbidity and mortality from tracheobronchial tears. ${ }^{3-5}$ Following non-penetrating trauma, other intrathoracic injuries are much more common than tracheobronchial injuries. Delays in diagnosis may occur because the signs are non-specific and these injuries are infrequent.

Clinical manifestations depend upon the location and extent of the tear as well as on the associated injuries. Nearly $10 \%$ of patients are asymptomatic but the majority present with dyspnoea, haemoptysis and/or cyanosis. ${ }^{6}$ Other common symptoms may be subtle and include localized pain, hoarseness, coughing, difficulty swallowing and stridor. Massive haemoptysis indicates an associated vascular injury and not an isolated tracheal or bronchial injury. ${ }^{1}$ Signs include bruising or swelling of the neck, tracheal deviation, abnormal breath sounds, tension pneumothorax, hypotension, cardiovascular collapse and Hamman's sign, a crunching sound synchronous with the heart beat. ${ }^{7}$ Subcutaneous emphysema is the most consistent physical finding. ${ }^{8}$ Pneumoperitoneum, usually associated with perforation of a viscus, has been described rarely. ${ }^{9}$ Acute symptoms may resolve with emergency treatment only to return in days or weeks once stenosis develops at the site of injury. ${ }^{10}$ Our patient presented with respiratory distress and hypotension of unknown aetiology.

Chest and neck $x$-rays are essential to verify an air leak and may reveal free air that is not detectable on physical examination. Cervical and thoracic subcutaneous emphysema are the most consistent radiological findings in tracheal injuries caused by blunt trauma; however, they are more commonly seen as nonspecific findings in the 
acute trauma patient after multiple rib fractures, penetrating chest wounds, or a difficult intubation. ${ }^{11}$ Subcutaneous emphysema that persists or increases should raise the suspicion of a continuing air leak from an airway injury, although disappearing emphysema does not rule out an airway tear." Pneumomediastinum is an early diagnostic sign but may also be a complication of dyspnoea, aggressive mechanical ventialtion or oesophageal rupture. If the tear is in the right main bronchus or the distal left bronchus, the air will usually be seen in the pleural space creating a pneumothorax. However, if the trachea or proximal left main bronchus is involved the air will commonly dissect centrally producing mediastinal and cervical emphysema. ${ }^{12}$ Failure to re-expand the lung with a chest tube under suction should increase the suspicion of a persistent leak from an airway injury. Other radiological findings associated with airway injuries include upper thoracic fractures of the clavicles, scapula, sternum or ribs, air surrounding a bronchus and interruption, sharp angulation or obstruction of the airways. Specific radiological evidence of tracheobronchial injury includes abnormal appearance of the endotracheal tube such as overdistension of the cuff and extraluminal position of the tip and the "fallen lung sign" which occurs when the affected lung collapses toward the lateral chest wall or diaphragm rather than the hilum. "The chest $x$-ray of our patient revealed pneumomediastinum, bilateral multiple rib fractures, bilateral chest tubes with no pneumothoraces, and extensive subcutaneous emphysema, all of which may be associated with tracheobronchial injury or simply other intrathoracic injuries.

In the diagnosis of injury to the tracheobronchial tree following blunt trauma, CT scan has become an important adjunct. ${ }^{13}$ It can aid the physician in those injuries which produce subtle radiographic findings on plain films of the chest and neck. In our case, CT scan findings not seen on chest $x$-ray included a non-expanding pneumothorax in spite of bilateral chest tubes. The CT scan demonstrated the endotracheal tube tip outside the trachea although it appeared in good condition on the plain film.

Bronchoscopic examination is the most valuable diagnostic and potentially therapeutic technique for acute injuries ${ }^{13-15}$ and should be performed early in concert with other diagnostic, resuscitative and therapeutic efforts. ${ }^{10}$ The findings may be clear but more often bronchoscopy is technically very difficult secondary to bleeding from the parenchyma or torn tracheobronchial mucosa. Bronchography, usually contraindicated because of the general condition of the patient, may miss small tears and should be reserved for chronic cases in which stenosis or occlusion may have occurred. ${ }^{10}$

Airway management is of paramount importance in these patients. Direct laryngoscopy may cause further deterioration in airway patency and intubation may result in the distal endotracheal tube lying outside the tracheal lumen, as in this case. Preferably, intubation is performed using fibreoptic bronchoscopy as guidance to visualize the injury. If the tear involves the trachea, the cuff of the endotracheal tube should be positioned below the injury, if possible. If a main bronchus is involved, the tube may be inserted into the main bronchus of the unaffected side. ${ }^{16}$ Double lumen tubes have been used to improve ventilatory function, facilitate intraoperative airway management and permit selective postoperative ventilatory support; however, there may be difficulty in proper placement, further airway injury may result, and suctioning may be inadequate. ${ }^{8}$ An endotracheal tube with a movable blocker (Univent) has been used perioperatively to block the injured bronchus. ${ }^{17}$ Bronchoscopic examination or intubation attempts may lead to complete tracheal transection or obstruction of the airway, therefore, preparation for immediate tracheostomy must be made before either is attempted. ${ }^{18}$ Patients with complete tracheal transection, laryngeal injuries or considerable airway obstruction may require tracheostomy under local anaesthesia. Tracheostomy may be necessary if the patient undergoes rapid deterioration or if the trachea cannot be quickly and successfully intubated. ${ }^{18} \mathrm{~A}$ transected trachea usually retracts into the mediastinum necessitating the use of a finger to locate the divided end of the distal trachea that should be grasped with a clamp to pull it into view, and to allow intubation. ${ }^{18}$ Ventilation may be maintained via a rigid bronchoscope while evaluating the airway injury. ${ }^{16}$ If available, femoral-femoral bypass under local anaesthetic may be instituted if attempts to secure the airway fail.

The operative management of tracheobronchial tears is dependent on the site of injury and repair is usually performed via thoracotomy. Originally it was felt that an inhalational agent with spontaneous ventilation would be beneficial intraoperatively as it would allow lower airway pressures. ${ }^{19}$ It is advisable not to use nitrous oxide which can expand pre-existing air collections. ${ }^{20}$ When positive-pressure ventilation is mandatory, high peak airway pressures should be avoided by either ventilating by hand, using small tidal volumes at higher rates, or employing pressure support ventilation. High frequency ventilation has been used to improve alveolar ventilation with decreased peak airway pressure, decreased tidal volume, and decreased air leak, and avoids an inflated endotracheal tube cuff against the suture line. ${ }^{21}$

Postoperatively the endotracheal tube should be pulled back above the repair site if the trachea cannot be extubated. Airway pressures should be minimized to avoid stress on the suture lines. 


\section{Conclusions}

Trauma to the intrathoracic tracheobronchial tree is a rare but potentially fatal injury. Physicians must maintain a keen vigilance and have a high index of suspicion of a tracheobronchial tear with blunt chest trauma. We describe a patient with a history of blunt chest trauma who presented with hypotension and respiratory distress. The patient's chest $x$-ray showed pneumomediastinum, rib fractures, and subcutaneous emphysema. Further findings on CT scan included a non-expanding pneumothorax in spite of bilateral chest tubes as well as the endotracheal tube tip outside the tracheal lumen. In spite of these findings, the diagnosis of tracheobronchial injury was not entertained until after the patient had difficulties with ventilation, endotracheal tube obstruction, and cardiac arrest. A high index of suspicion may have prevented these problems and addressed the primary pathology sooner. Patients with a history of blunt chest trauma and findings suggestive of airway injury including mediastinal emphysema or haemoptysis should undergo early bronchoscopy. A critical evaluation of the patient clinically, radiologically, and bronchoscopically should lead to earlier diagnosis resulting in improved airway management and lower morbidity and mortality of tracheal and bronchial injuries.

\section{Acknowledgment}

Assistance from Dr. C. Brian Warriner in reviewing the manuscript is gratefully acknowledged.

\section{References}

1 Kelly JP, Webb WR, Moulder PV, Everson C, Burch BH, Lindsey ES. Management of airway trauma I: Tracheobronchial injuries. Ann Thorac Surg 1985; 40: 551-5.

2 Grover $F L$, Ellestad CE, Arom KV, Root $H D$, Cruz $A B$, Trinkle $J K$. Diagnosis and management of major tracheobronchial injuries. Ann Thorac Surg 1979; 28: 384-91.

3 Eijgelaar A, van der Heide JNH. A reliable early symptom of bronchial or tracheal rupture. Thorax 1970; 25: $120-5$.

4 Chavez CM, Anas P, Conn JH. Surgical approach to injuries of the cervical trachea. South Med J 1972; 65: 659-60.

5 Meinke AH, Bivins BA, Sachatello $C R$. Selective management of gunshot wounds to the neck. Am J Surg 1979; 138: 314-9.

6 Chesterman JT, Satsangi PN. Rupture of the trachea and bronchi by closed injury. Thorax 1966; 21: 21-7.

7 Palmer MT, Turney SZ. Tracheal rupture and atlantooccipital dislocation: case report. J Trauma 1994; 37: 314-7.
8 Shimazu T, Sugimoto H, Nishide K, et al. Tracheobronchial rupture caused by blunt chest trauma: acute respiratory management. Am J Emerg Med 1988; 6: 427-34.

9 Barnhart GR, Brooks JW, Kellum JM. Pneumoperitoneum resulting from tracheal rupture following blunt chest trauma. J Trauma 1986; 26: 486-8.

10 Nakayama $D K$, Rowe MI. Intrathoracic tracheobronchial injuries in childhood. Int Anesthesiol Clin 1988; 26: 42-9.

11 Unger JM, Schuchmann GG, Grassman JE, Pellett JR. Tears of the trachea and main bronchi caused by blunt trauma: radiologic findings. American Journal of Roentgenology 1989; 153: 1175-80.

12 Guest $J L J r$, Anderson $J N$. Major airway injury in closed chest trauma. Chest 1977; 72: 63-6.

13 Palder SB, Shandling B, Manson D. Rupture of the thoracic trachea following blunt trauma: diagnosis by $C A T$ scan. J Pediatr Surg 1991; 26: 1320-2.

14 Burke JF. Early diagnosis of traumatic rupture of the bronchus. JAMA 1962; 181: 682-6.

15 Westaby $S$. Injury to the major airways. Br J Hosp Med 1985; 34: 210-20.

16 Symbas PN, Justicz AG, Ricketts RR. Rupture of the airways from blunt trauma: treatment of complex injuries. Ann Thorac Surg 1992; 54: 177-83.

17 St. Cyr JA, Fullerton DA, Zamora M, Hopeman AR. Tracheobronchial disruption: postoperative management with jet ventilation to minimize airway pressures. $\mathrm{J}$ Cardiovasc Surg 1994; 35: 79-81.

18 Ayabe H, Tsuji A, Akamine S, Tagawa Y, Kawahara K, Tomita $M$. Combined transection of the trachea and esophagus following cervical blunt trauma. Thorac Cardiovasc Surg 1993; 41: 193-5.

19 Santora $A H$, Wroe WA. Anesthetic considerations in traumatic tracheobronchial rupture. South Med J 1986; 79: 910-1.

20 Feinstein $R$, Owens WD. Anesthesia for ear, nose, and throat surgery. In: Barash PG, Cullen BF, Stoelting RK. (Eds.). Clinical Anesthesia, 2nd Ed. Philadelphia: JB Lippincott, 1992: 1122.

21 Dreyfuss D, Jackson RS, Coffin LH, Deane RSD, Shinozaki $T$. High-frequency ventilation in the management of tracheal trauma. J Trauma 1986; 26: 287-9. 